\title{
New Light on Ancient Architecture and Mathematics
}

\author{
Kim Williams ${ }^{1}[$ \\ Published online: 12 April 2021 \\ (c) Kim Williams Books, Turin 2021
}

\begin{abstract}
Editor-in-Chief Kim Williams examines the way intersections of architecture and mathematics in ancient architecture are being brought to light thanks to increased information and new technologies, and introduces the articles in Nexus Network Journal vol. 23 no. 2 (2021).
\end{abstract}

Keywords Nexus Network Journal · Methods of laying out · Methods of analysis

Despite centuries of studies and scholars' best efforts at understanding, many mysteries still shroud the fragments of ancient buildings and cities that have come down to us. Today, new light is being shed on artifacts that have eluded earlier attempts at explanation. This is due in part to a new wealth of information placed at our fingertips thanks to advances such as drone photography and satellite observation, made available by sites such as Google Earth and GeoEye. It is also due to new technologies capable of capturing massive data, leading to new means of visualization and analysis such as point clouds. However, most advances in our understanding are due to researchers' persistence in studying, deconstructing, reconstructing and decoding, using whatever means provides them with the most information.

This issue of the Nexus Network Journal presents a collection of research on built artifacts of epochs going as far back as $1500 \mathrm{BC}$, and ranging geographically from Europe to Egypt, from the Middle to the Far East. The topics addressed fall, broadly speaking, into two main groups. The first is concerned with techniques of laying out, that is, how mathematical knowledge was applied in disposing elements into a meaningful patterns of order. The second deals with methods of analysis that allow us to identify and build upon such patterns of order.

Kim Williams

kwb@kimwilliamsbooks.com

1 Kim Williams Books, Corso Regina Margherita, 72, 10153 Turin, Italy

Birkhäuser 


\section{Laying Out}

The Nexus Network Journal has never before published a three-part research, but the lengthy and detailed examination of three types of mazes is certainly worthy of this innovation. Bernard Parzysz brings to us "Geometry of Ancient Mazes" in three parts: Part I: 'Cretan' Mazes; Part II: 'Roman' Mazes; and Part III: 'Church' Mazes. The aim is to investigate the processes implemented for conceiving and setting up major types of mazes in various media (stone, mosaic, painting, ceramic, coins...) from prehistoric times, through Roman Empire and the Middle Ages, and even up to the modern age. Parzysz shows how the identification of a model enables the proposal of a setting-up process that makes it possible to memorize the designs and reproduce them by heart.

Anja Wutte and José Pinto Duarte worked to define an analytical method to characterize a Late Period tomb architecture of the Thebes West and encode the results into a shape grammar. In "Shape Grammar as a Typology Defining Tool for Ancient Egyptian Funerary Monuments" they begin by introducing the architectural morphology of the complexes, then make explicit the set of rules of the proposed grammar, using one of a set of ten monuments as an example how its layout derived from the grammar. They conclude with a discussion of further possible outcomes and possibilities of the use of shape grammars in archaeological studies.

In "The Mathematics of the Viereckschanzen of the La Tène Culture", Albert Kainzinger argues that Iron Age La Tène culture's construction of square ditched enclosures provides evidence of their practical knowledge of fundamental mathematical and geometrical concepts such as the Pythagorean theorem (in terms of Pythagorean triangles), Thales' theorem, square root approximations, the concept of similarity, and the concept of commensurability.

In "The Conceptual Design of the Octagon at Thessaloniki", Demetrius Savvides examines a diagram inscribed in stone found in the famous Octagon of the Galerian Palace complex, which consists of several extremely complicated geometric entities such as radials, cycles, squares and interlaced squares which intensively form sequences of octagrams. Savvides posits that this might provide the earliest evidence of a conceptual design in architecture. His analysis proceeds by means of one geometrical model to explain the geometrical patterns on the Octagon diagram and another to describe the Octagon's ground plan.

It is well known that early Christian churches were ideally meant to be oriented along an East-West axis, although the interpretations of exactly what this meant varied. The research team of Josep Lluis i Ginovart, Cinta Lluis Teruel and Iñigo Ugalde Blázquez, in "Cosmology and Precision in the Val d'Aran" begin with the sources that proscribe this rule, then identify a set of fifteen eleventh-century churches in Spain's Val D'Aran that appear to adhere to it. Finally, they discuss various methods that could have been known and used by the builders and clergy to achieve this aim.

The familiar geometric pattern called the 'quincunx', based on a nine-square grid, has been used as both decoration and a planning devise for architecture 
since at least the Roman Republic era, but rarely has a geometric motif been so constantly resurrected. As Fabio Colonnese writes in "Mapping the Persistence and Evolution of the Quincunx", the quincunx "spread in the Byzantine era; it flourishes during the Renaissance, either in combination or as an alternative to the Vitruvian proportioning criteria; it suffers from a process of mathematization in the eighteenth century; it arrives at the twentieth century in the form of the so-called "nine-square grid problem" and is further re-evaluated in its historical prospective at the end of the century, in the Post-modern context". Colonese's examination provides a fine exposition of the persistence of form.

\section{Methods of Analysis}

In "Parameterizing the Curvilinear Roofs of Traditional Chinese Architecture", the research team of Yuan Shen, Enhe Zhang, Yanxiao Feng, Siyuan Liu, Julian Wang, present the parameterization of the design and construction rules for the distinctive roofs that characterize traditional Chinese architecture. Basing themselves on the Yingzao fashi, they were able to transform the design and building rules for complex curvilinear roofs into mathematical models.

Examples of the vernacular architectural building type known as a "cocó", a domed dry-stone construction, have been a part of the landscape of the Iberian Peninsula since the beginning of the twelfth century. For the research team of Cèlia Mallafrè Balsells, Josep Maria López Besora, Agustí Costa Jover and Sergio Coll Pla, registering and analysing it proved to be a special challenge due to the extremely irregular nature of the artefacts. In "Register of Dry Stone Domes. Simplified Method for Point Clouds" they explain how it was precisely this difficulty that allowed them to focus on defining a method that makes it possible to simplify the number of points obtained through photogrammetry, and at the same time complete the cloud of points as precisely as possible.

Asli Agirbas and Gulnar Yildiz, carried out their study on the "Origin of Irregular Star Polygons in Ground Projection Plans of Muqarnas" by means of a shapegrammar analysis of the muqarnas at the main gate of the Atik Valide Mosque, Istanbul, allowing them to conclude that the ground plan projection was based on rosette-like grids formed from ellipses. Further, by geometrically decomposing the ground projection plan, they were also able to obtain a parametric 3D geometry of the muqarnas.

Ian Verstegen, in "Common Scales in Military Maps from the Fortification Projects for Rome", undertakes a scale analysis of the fortification drawings of Antonio da Sangallo the Younger for the Vatican Borgo, comparing the inscribed scales and real-world dimensions. This allow him to compare the scales used for different kinds of drawings raises and thus consider questions about the circulation and reproduction drawings at a series of scales useful to the work of an architect or cartographer. It also enables him to related San Gallo's work to Bufalini's great map of Rome of 1551, positing that the work of the latter developed directly from that of the former. 
This rich issue of the Nexus Network Journal brings into focus once again the close relationships between architecture and mathematics that has existed for ancient builders. What it also allows us to see is how modern techniques and technologies are continuing to solve some of the mysteries of "how they did it".

Publisher's Note Springer Nature remains neutral with regard to jurisdictional claims in published maps and institutional affiliations.

Kim Williams received her degree in Architectural Studies from the University of Texas in Austin. She became interested in mathematics and architecture while writing Italian Pavements: Patterns in Space (Anchorage Press, 1997) about the role of decorated pavements in the history of Italian architecture, and it has been her field of research ever since. She is the founder and director of the international, interdisciplinary conference series "Nexus: Relationships Between Architecture and Mathematics", and is the founder and co-editor-in-chief (with Michael Ostwald) of the Nexus Network Journal. She is the author of Daniele Barbaro's Vitruvius of 1567 (Birkhäuser, 2019). Her forthcoming book, with Cosimo Montelone, is Daniele Barbaro's Perspective of 1568 (Birkhäuser, 2021). 